\title{
Improving field establishment of cacao (Theobroma cacao) through mulching, irrigation and shading
}

Article

Accepted Version

Acheampong, K., Daymond, A. J., Adu-Yeboah, P. and Hadley, P. (2019) Improving field establishment of cacao (Theobroma cacao) through mulching, irrigation and shading. Experimental Agriculture, 55 (6). pp. 898-912. ISSN 0014-4797 doi: https://doi.org/10.1017/S0014479718000479 Available at https://centaur.reading.ac.uk/81088/

It is advisable to refer to the publisher's version if you intend to cite from the work. See Guidance on citing.

To link to this article DOI: http://dx.doi.org/10.1017/S0014479718000479

Publisher: Cambridge University Press

All outputs in CentAUR are protected by Intellectual Property Rights law, including copyright law. Copyright and IPR is retained by the creators or other copyright holders. Terms and conditions for use of this material are defined in the End User Agreement.

www.reading.ac.uk/centaur 
Central Archive at the University of Reading

Reading's research outputs online 
Running title: Shade and soil water promote cacao establishment

\title{
Improving field establishment of cacao (Theobroma cacao) through mulching, irrigation and shading
}

\author{
K. Acheampong ${ }^{1 *}$, A. J. Daymond ${ }^{2}$, P. Adu-Yeboah ${ }^{1}$ and P. Hadley ${ }^{2}$
}

${ }^{1}$ Cocoa Research Institute of Ghana, P.O. Box 8, Tafo-Akim, Ghana

${ }^{2}$ School of Agriculture, Policy and Development, The University of Reading, Whiteknights, Reading, RG6 6AR, UK

*Corresponding author: oyacheampong@yahoo.com

SUMMARY

Establishment of young cacao trees in West Africa can be severely impeded by the on-set of the dry season. To address this issue, a field experiment was conducted in Ghana to examine whether different mulch treatments and irrigation applied during the dry season combined with over-head shade could improve survival, early growth and yield of cacao. The mulch treatments used were polyethylene film and coffee husks placed around the young plants. Irrigation was used as a positive control and no mulching or irrigation was a negative control. Three shade regimes were provided through different arrangements of Gliricidia sepium and plantains. Four different cacao clones were used in the study in a replicated split-plot design. Early growth of cacao was stimulated under the irrigation and plastic mulch treatments. Higher rates of photosynthesis during the dry season appeared to underlie these increases. Significantly higher early yields were also observed under the irrigation and coffee mulch treatments compared to the control. Plant survival varied significantly between treatments; irrigation was associated with the highest plant survival (94\%), followed by the plastic mulch treatment (91\%), coffee husk ( $82 \%)$ and the control (70\%). There was also an increase in survival when more intense shading was used. Under zero mulch conditions, differences in survival were observed between clones. The clones P 30 [POS] and SCA 6 were more sensitive to drought (in terms of survival) than PA 150 and T 79/501. It is concluded that relatively simple mulching techniques or controlled irrigation in conjunction with appropriate shade management can significantly improve early establishment and cropping of cacao.

\section{INTRODUCTION}

Cacao is cultivated throughout the humid tropics and approximately $71 \%$ of global 37 production of cocoa beans is within West Africa (ICCO, 2016). In order to maintain a livelihood, farmers periodically need to rehabilitate their farms by replacing old trees with higher yielding 39 varieties. A particular challenge in West Africa is that establishment of young trees can be hampered by the onset of the dry season, which typically occurs between December and February (Toxopeus, 1970). The degradation of soils that have previously been planted with cacao exacerbates the challenge of establishment since the loss of soil organic matter reduces the water43 holding capacity of the soil. For example, Ayanlaja (1983) compared some edaphic parameters 44 (pH, \% N and \% organic 
carbon) of old cacao soils with counterpart forest soils and found the former to have values significantly lower than values considered to be adequate for cacao. Furthermore, global climate change is resulting in a harsher dry season. Stanturf et al. (2011) report an average increase in air temperature of $1{ }^{\circ} \mathrm{C}$ in Ghana since 1960 . Moreover, dry season length and severity have increased in West Africa rainforest regions (Malhi \& Wright 2004). Where localised deforestation has occurred there can be expected to be less buffering of the microenvironment. As a consequence of all of these factors, there is an increasing need for improved establishment methods and cacao varieties which are more tolerant to water deficit.

Cacao is relatively sensitive to water deficit (Raja Harun and Hardwick, 1988). The use of mulching has the potential to reduce losses during establishment if applied before the onset of the first dry season (Wasowicz and Havord, 1951). If properly applied, mulching will improve soil moisture status by reducing soil moisture evaporation. Mulching is capable of creating a porous, better aerated soil layer with improved water holding capacity, making the soil more suitable for the development of plant roots. In addition, organic mulches eventually break down to release variable but often significant amounts of plant nutrients usually including nitrogen, phosphate and potassium as well as trace elements. Unlike inorganic fertilisers, organic mulches release their nutrients slowly as they decompose. Despite the numerous benefits of mulching, the practice is not widely used in West Africa and only limited information on its effect on cacao establishment is available. An attempt was made in Ghana by Frimpong and Akuoko (1995) to study the combined effect of plantain pseudo-stems (used as a mulching material) and a water-absorbing polymer ('Grow Soak 400') on cacao seedling survival and growth under field conditions. The first year's results indicated a $20 \%$ greater seedling survival under the 'mulch-only' treatment than under the control treatment where there was no application of mulch.

The use of irrigation provides another potential route towards improved establishment. Carr and Lockwood (2011) reported that despite its known sensitivity to water stress there is a paucity of reliable, field-based published data of practical value on the responses of cacao to irrigation. The provision of over-head shade also contributes towards the success of cacao establishment and attempts to reduce the cost of establishing cacao by reducing or eliminating "temporary" shade have not shown consistent success. This is explained by the fact that cacao has a number of attributes that are typical of shade species. These include low photosynthetic rates (Daymond et al., 2011) and a high sensitivity to photoinhibitory stress (Galyuon et al., 1996) Therefore, shade provided by companion plants to ameliorate physiological stress caused by high light intensities and high evapotranspiration is generally considered a requirement, especially, of young cacao (Ahenkorah et al., 1974). Acheampong et al. (2013) conducted a nursery experiment to assess the shade requirement of four cacao clones and observed seasonal variations in the shade requirement of young cacao, with the shade requirement being higher in the dry season. Here, the same clones have been combined into treatments of varying shade and mulch/irrigation during the dry season. Combining those important factors in one experiment was expected to provide further insight into the link between improved agro-ecological conditions and the field establishment of cacao.

The aim of this study is to establish whether simple mulching practices under field conditions can maintain enough soil water for the successful establishment of young cacao trees while shade is provided by other plant species. The mulching treatments were compared to a 
'control' treatment (devoid of any intervention towards soil moisture management) as well as a comparison with irrigation to maintain soil moisture levels. The mulching/irrigation and control treatments were studied under three shade intensities. Furthermore, the study considers to what extent there is genotypic variation in establishment rates and whether cacao genotypes respond differently to the aforementioned treatments.

\section{MATERIALS AND METHODS}

\section{Experimental site and soil analysis}

An area (2.4 ha) at the Cocoa Research Institute of Ghana (6 $6^{\circ} 13$ '34.46" N; 0²1'37.92”' W; $220 \mathrm{~m}$ a.s.l.) was selected for the experiment. Although this work was done as a replant on a site that fell under the ideal soil type classification (based on geology and topography) the site had previously carried a number of previous cacao trials of various durations in succession without soil nutrient replenishment. Results from an initial soil nutrient analysis were compared with standard values for cacao soils (Smyth, 1966) and the soil phase (which usually depends on the previous history of land use) was rated as 'sub-optimum' for cacao establishment. The nutrient analysis showed that, whereas the $\mathrm{pH}$ level and available phosphorus were comparable with standard values, nitrogen, organic matter, carbon and the carbon/nitrogen ratio were low (Table 1). Land preparation (carried out between December 2006 and May 2007) involved clear felling of the site and stumping out the old cacao trees.

\section{Plant material}

Four cacao genotypes were used in the study: T 79/501, PA 150, SCA 6, representing, respectively, a vigorous, an intermediate, and a low vigour genotype, and P 30 [POS], representing West African Amelonado, which is a traditionally cultivated cacao genotype in Ghana used in this work as a control. The clonal material was propagated by side grafting onto a common six-month old seedling rootstock ( $\mathrm{T}$ 60/887 x Amelonado). The scion was inserted below the point of attachment of the cotyledons of the rootstock to prevent chupons growing from below the graft union. The cacao was raised in large $(320 \times 375 \mathrm{~mm})$ polythene bags $1.5 \mathrm{~km}$ from the experimental site. Each growing bag had been provided with a $35 \mathrm{~mm}$ diameter drainage hole at the bottom and contained $12 \mathrm{~kg}$ of top soil. The bottoms of the growing bags were placed on a plastic sheet $(0.13 \mathrm{~mm}$ thick $)$ spread on the nursery floor to discourage seedlings rooting through the bottoms and penetrating the soil underneath. Material of the same age ( 6 months after grafting) and approximately the same size $($ girth $=8 \mathrm{~mm}$; height $=360 \mathrm{~mm}$ ) were selected for field planting.

\section{Experimental design}

The experiment was laid out as a split-plot with mulch as the main plot factor, and shade level $\mathrm{x}$ cacao genotype combinations as the sub-plot factors. There were four blocks each containing 48 sub-plots measuring $9 \times 12 \mathrm{~m}$. Each sub-plot contained six experimental cacao plants planted at 3 x 3 m spacing in June 2007 and these were surrounded by a guard row of cacao plants (shared by adjacent sub-plots). Results of the experiment were analysed (using Genstat) by analysis of variance, and significance among mean values was determined by least significant difference (LSD) values, where $\mathrm{P}=0.05$. 
Field planting of cacao and temporary shade plants

A month prior to transplanting the cacao, the nursery shade was reduced gradually to acclimatise the seedlings until it was completely removed one week before transplanting. Three temporary shade regimes (light, medium and heavy) were created by planting Gliricidia sepium and plantains (Musa sapientum) in different arrangements. Like the cacao, the plantain suckers were planted at $3 \times 3 \mathrm{~m}$ and the Gliricidia stakes were planted as follows:

1) The arrangement of the 'light' shade regime consisted of $1.5 \mathrm{~m}$ tall Gliricidia sepium stakes and plantains planted in April 2007 at $3 \times 3$ m each.

2) The 'medium' shade regime consisted of the 'light' shade treatment plus three stands of 0.5 $\mathrm{m}$ tall Gliricidia sepium stakes planted (in August 2007) at $0.6 \mathrm{~m}$ away from the cacao in a triangle to enclose the cacao.

3) The 'heavy' shade treatment arrangement was the same in all respects as the 'light' shade except that, in relation to the position of the young cacao trees, the plantain suckers were planted towards the west and at $0.6 \mathrm{~m}$ (instead of $1.5 \mathrm{~m}$ ) away from the cacao plants.

\section{Shade measurement}

The proportion of light intercepted by the shade trees was measured twice in each of the three seasons (on September 5 and October 22, 2007; December 17, 2007 and February 11, 2008; April 8 and June 2, 2008 for the minor rainy, the dry and the major rainy seasons, respectively) by means of a 'SunScan' Canopy Analysis System (SS1; Delta-T, Cambridge, UK). Measurements were taken around midday with the probe (light sensor) held just above the cacao plants, below the canopy of the nearest shade plants.

\section{Mulch treatments}

Considering irrigation as a mulch treatment (by reason of its enhancing effect on soil moisture as is the case with mulches in general) four 'mulch' treatments were applied as follows: (1) No mulch (control); (2) Irrigation of experimental plants (positive control); (3) Black polyethylene film (as plastic mulch) spread at the base of the cacao trees in October and removed in March the following year; and (4) $15 \mathrm{~kg}$ of decomposed coffee husk, split-applied around the base of cacao test plants in October and November.

The irrigation system was installed in December 2007. This consisted of a water pump which pumped water from a reservoir through an inlet pipe into a 3,825 litre-capacity plastic tank mounted on a $2.5 \mathrm{~m}$ high concrete platform. Water from the overhead plastic container was distributed under gravity through a delivery system consisting of perforated $12.5 \mathrm{~mm}$ diameter plastic pipes (Duraplast, Ghana Ltd.), which served individual experimental plants directly in designated plots. The pipes were buried (in a sub-surface system) to a depth of $150 \mathrm{~mm}$ beneath the soil surface to avoid damage during cultural operations. Water from the perforated pipes formed a continuous wetted area around the base of each irrigated tree. The outlet from the overhead tank was fitted with a meter to enable measurement of water supplied to the experimental plants. Each plant was supplied with 2.7 litres of water (equivalent to about $12.5 \mathrm{~mm}$ of rainfall) twice a week during the 2007/2008 dry season (December 2007 through to the end of February 2008) resulting in an area with a radius of about $400 \mathrm{~mm}$ around the young cacao being continually wet. This watering regime was repeated during the 2008/2009 dry season. 
After clean-weeding the plots, a meter-wide black polyethylene film (thickness $=0.13 \mathrm{~mm}$ ) was spread at the base on either side of experimental plants (cacao and shade plants that were within the radius) in October 2007 as an inorganic mulch in designated plots to conserve soil water around the plants. Short wooden pegs were used to hold the polyethylene film in place. The polyethylene film was removed in March 2008 (the end of the 2007-2008 dry season). It was spread again in October 2008 and removed in March 2009. For coffee husk mulch, $15 \mathrm{~kg}$ of decomposed coffee husk was split-applied in equal doses as a mulch to core cacao trees in designated plots in October and late November 2007.

\section{Soil moisture determination}

Soil moisture content of the experimental site was measured at four depths $0.1,0.2,0.3$ and $0.4 \mathrm{~m}$ by means of a $0.4 \mathrm{~m}$ long soil moisture probe (Delta-T, Cambridge, U.K; model PR2/4). The measurements were conducted twice in the dry season in January and February of 2008 and 2009 within the different mulch treatments.

\section{Gas exchange measurements}

Starting from September 2007 an infrared gas analyser (LC pro+, ADC Bioscientific, UK) was used to determine rates of stomatal conductance and photosynthesis of the cacao trees within the different treatments. The measurements were carried out on two days in each of the three seasons of the 2007/2008 crop year (from September/October 2007 for the minor rainy season; January/February 2008 for the dry season; March/May 2008 for the major rainy season) between $0900 \mathrm{~h}$ and $1100 \mathrm{~h}$ on three out of the six plants of each clone in all blocks under all the mulch and shade treatments. For each tree, measurements were conducted on the youngest fully expanded hardened leaf of a flush. These seasonal measurements, which were made at ambient environmental conditions, were repeated in the 2008/2009 crop season. Mean PAR incident on leaf surface for the major, minor and dry seasons was 729,474 and $779 \mu \mathrm{mol} \mathrm{m}^{-2} \mathrm{~s}^{-2}$ in $2007 / 8$ and 813,578 and $1091 \mu \mathrm{mol} \mathrm{m}^{-2} \mathrm{~s}^{-2}$ in 2008/9, respectively. Mean air temperature for the major, minor and dry seasons was $37.5,33.1$ and $37.8{ }^{\circ} \mathrm{C}$ in $2007 / 8$ and $35.5,28.5$ and $35.5{ }^{\circ} \mathrm{C}$ in $2008 / 9$, respectively.

\section{Microclimate measurements}

Rainfall data were collected at a nearby weather station. In addition, data loggers (Tinytag, Gemini Data Loggers, UK) placed in Stevenson screens were used to record the temperature and relative humidity at 15-minute intervals in the three shade environments.

\section{Plant growth, survival and yield}

Stem diameter (at $0.2 \mathrm{~m}$ from ground level) and height measurements of all experimental cacao trees were conducted once every two months from September 2007. Measured values were transformed into stem volume indices using the formula: Stem Volume $=(1 / 3) \pi(1 / 4)(\text { stem diameter })^{2}$ $\mathrm{x}$ height (Oliet et al., 2004). 
Cacao tree survival rate was determined in September 2007 and during the last week of March 2008 and 2009. The numbers surviving were expressed as a percentage of the total number planted per treatment. The data were arc-sine transformed before analysis.

Each year the pod index (the number of pods that gives one kilogramme of dried cocoa beans at $7 \%$ moisture) was determined for each of the four cacao genotypes. Pod harvesting was done every 3-4 weeks from the six trees within each $18 \mathrm{~m}^{2}$ core plots when the pods were ripe. The pod indices were used as the basis for determining the dry bean yield per treatment per year.

\section{RESULTS}

\section{Meteorological Data}

The mean daytime relative humidity, temperature and calculated vapour pressure deficit across the different seasons and under the shade treatments at the times of data collection are summarised in Table 2. The average vapour pressure deficit was $2.26 \mathrm{kPa}$ in the dry season compared with 1.15 $\mathrm{kPa}$ and $0.51 \mathrm{kPa}$ in the major rainy and the minor rainy seasons, respectively. Mean vapour pressure deficits under the light shade were $0.11,0.34$ and $0.71 \mathrm{kPa}$ higher compared with the heavy shade treatment in the minor rainy, dry and major rainy seasons, respectively. Air temperatures were on average $2.6^{\circ} \mathrm{C}$ and $8.9^{\circ} \mathrm{C}$ higher in the dry season compared with the major and minor wet seasons, respectively (Table 2). Also, modulations were noted in mean daytime temperatures under the shade treatments: Mean temperatures under light shade were 1.3, 1.6 and $0.6^{\circ} \mathrm{C}$ higher compared with the heavy shade treatment in the minor rainy, dry and major rainy seasons, respectively. The major and minor rainy seasons of 2007 recorded 147.0 and $299.6 \mathrm{~mm}$ rainfall, respectively, while the rainfall during the dry season of the 2007-2008 crop year was 33.8 $\mathrm{mm}$. Rainfall was higher in the minor rainy season than the major rainy season and this was unexpected for the cacao growing belt of Ghana (Owusu and Waylen, 2013). The major rainy season of 2008 experienced more rain $(216.2 \mathrm{~mm})$ compared with the major rainy season of 2007 but it was still lower than that of the 2007 minor rainy season.

\section{Light transmitted by the overhead shade}

The percentage of incident light transmitted by the overhead shade was $46 \%$ to $50 \%, 43 \%$ to $46 \%$ and $37 \%$ to $43 \%$ for the "light", "medium" and "heavy" shade treatments, respectively.

\section{Soil water content under the mulch treatments}

Soil moisture content during the dry season of 2007/2008 was significantly higher $(\mathrm{P}=0.04)$ under the mulch treatments compared with the control (Figure 1). Generally, the soil water content was similar under the plastic mulch and the irrigation treatments, except at $0.1 \mathrm{~m}$ depth where it was higher under irrigation. Soil moisture was lower under the coffee mulch treatment than the plastic mulch and irrigation treatments, although still somewhat higher than the control. The effect of shade on soil water content was not measured. 


\section{Stomatal conductance and photosynthesis}

Stomatal conductance of the cacao trees was highest during the major rainy season, lower during the minor rainy season and considerably supressed in the dry season ( $\mathrm{P}=0.006$ for seasons) (Figure 2). Differences between mulch and irrigation treatments were proportionally greater during the major rainy season and for the clones SCA 6 and T 79/501 during the dry season compared with the minor rainy season (the season $\mathrm{x}$ mulch term was on the borderline of significance, $\mathrm{P}=0.08$ ). Overall, there were no significant differences between genotypes.

There was significant $(\mathrm{P}<0.001)$ seasonal variation in rates of net photosynthesis; the mean photosynthetic rate in the major rainy season was 2.2 and 3 times greater than the rates in the minor and dry seasons, respectively (Figure 3 ). Considered over the whole period, only slight differences were found between the mulch treatments. However, there was a significant $(\mathrm{P}=0.019)$ season $\mathrm{x}$ mulch interaction on photosynthesis. In the two rainy seasons there were no consistent trends between mulch treatments. However, during the dry season the photosynthetic rate under the zero mulch treatment (averaged across the four clones) was 9\%, 33\% and 68\% lower than the rates in plants provided with the coffee husk mulch, irrigation and plastic mulch treatments, respectively. On average, rates of photosynthesis were similar between genotypes, although there was a significant mulch $x$ genotype interaction $(\mathrm{P}=0.025)$. No particular trend was observed between clones in the wet seasons (Figure 3).

\section{Tree survival}

Overall, by the end of the second year $74 \%, 85 \%$ and $82 \%$ of the trees survived under the light, medium and heavy shade treatments, respectively $(\mathrm{P}=0.016$; Figure 4). Significant differences $(\mathrm{P}=0.003)$ were observed on the survival rates of the cacao genotypes by the end of the second year; 76\% of SCA 6, 78\% of P 30 [POS], 85\% of PA 150 and $86 \%$ of T 79/501 survived across the imposed treatments of shade and mulch/irrigation. With respect to the soil moisture management treatments $70 \%, 82 \%, 91 \%$ and $94 \%$ of the trees survived under the zero mulch, coffee husk mulch, plastic mulch and irrigation treatments, respectively $(\mathrm{P}=0.022)$. Relative losses under no mulch were greater for some clones than others, the clone $\mathrm{x}$ mulch interaction term being on the borderline of significance $(\mathrm{P}=0.072)$. For example, at the end of the second year the percentage of trees surviving under no mulch conditions compared with irrigation were $80 \%$ and $98 \%$, respectively for $\mathrm{T} 79 / 501$, whereas the equivalent figures for P 30 [POS] were $45 \%$ and $90 \%$, respectively (average across shade treatments). There was a general tendency of greater differences between shade treatments under the no mulch treatment compared with the other soil moisture management treatments (shade $\mathrm{x}$ mulch interaction $\mathrm{P}=0.074$ ). All other interactions were not significant.

\section{Stem volume}

After the first year, plants that were subjected to the mulch interventions had larger $(\mathrm{P}=0.006)$ stem volumes than those under no mulch. Plants that received the irrigation treatment had, on average, the largest stems followed by the plastic mulch, coffee mulch and zero mulch treatments, respectively. The mulch $\mathrm{x}$ genotype interaction was not statistically significant. The same pattern was observed after the second year (Figure 5); the stem volumes of cacao receiving the irrigation, plastic mulch, coffee husk and zero mulch were $716.4,700.8,671.5$ and $655.9 \mathrm{~cm}^{3}$, respectively. 
Differences $(\mathrm{P}=0.001)$ were also observed between clones in their stem volumes at the end of the second year (Figure 5). The largest genotype, PA 150 (average stem volume $=766.9 \mathrm{~cm}^{3}$ ) was $1 \%$, $20 \%$, and $31 \%$ larger than T 79/501, P 30 [POS] and SCA 6, respectively.

\section{Yield}

Significant differences $(\mathrm{P}=0.011)$ were recorded between the genotypes in dry cocoa bean yield in the first year of cropping (Figure 6). PA 150, T 79/501, SCA 6 and P 30 [POS] produced 201.4 $\mathrm{kg}, 185.4 \mathrm{~kg}, 170.3 \mathrm{~kg}$ and $161.5 \mathrm{~kg}$ of dry beans, respectively. Significant differences in yields were observed between the mulch/irrigation treatments $(\mathrm{P}=0.001)$ such that the highest yields were observed under the irrigation and coffee husk treatments, with those under the plastic mulch and zero mulch treatments being considerably lower. No significant effects of shade were observed nor were there significant interactions between the factors under study.

\section{DISCUSSION}

The observation that soil moisture was higher under the mulch treatments (Figure 1) is consistent with earlier reports on organic mulches, which have long been noted to improve soil water retention. The use of plastic film mulches for this purpose is more recent. However, such mulches have also been shown to be effective in retaining soil water for agricultural purposes (Liu et al., 2009, Jagoret and Jadin, 1992). The observed higher stomatal conductance and, consequently, photosynthetic rates of trees subjected to the irrigation and plastic mulch treatments in the dry season (Figures 2 and 3) demonstrates that soil moisture, if adequate, may be associated with a partial amelioration of the suppressive effect of drought in cacao by improving the plant water status (Joly and Hahn, 1989a). The observation that stomatal conductance and photosynthesis of the cacao trees were much higher in the major rainy season compared to the dry season, irrespective of mulching (Figures 2 and 3), suggests that the photosynthetic rate was influenced by changes in vapour pressure deficit. With the high water vapour pressure deficit of the dry season (Table 1), tree water uptake probably did not match the rate of transpiration, resulting in a restriction of stomatal opening to reduce internal water deficit. A number of previous studies on cacao have demonstrated stomatal sensitivity to increased vapour pressure deficit (Raja Harun and Hardwick, 1988, Balasimha et al., 1991).

Although stomatal limitation was essentially alleviated in the minor rainy season, the cloudy situation was likely to have contributed to the reduction in the rate of $\mathrm{CO}_{2}$ fixation compared with the major wet season (Table 1, Figure 3). This confirmed an earlier report that in the minor rainy season light becomes a limiting factor to $\mathrm{CO}_{2}$ fixation (Acheampong et al., 2013). Furthermore cooler temperatures were observed during the minor rainy season; such sub-optimal temperatures are known to suppress photosynthesis in cacao (Daymond and Hadley, 2004). Thus, conditions of the major rainy season of West Africa best support the realisation of high net photosynthesis. These include the higher light intensity, low water vapour pressure deficit and increased soil water.

Tree growth rates, measured as stem volume, were higher under the mulch treatments (Figure 5) evidently as a result of the maintenance of higher rates of photosynthesis during the dry season (Figure 3). Water stress of sufficient intensity is capable of causing lasting disruption to the photosynthetic apparatus of young cacao (Joly and Hahn, 1989a). Here, we also observed higher 
survival rates when mulch treatments were imposed (Figure 4), the survival rate using the plastic mulch treatment being comparable to that of irrigation (positive control). In addition to conserving soil moisture, the mulch treatments could also have reduced stress by reducing root zone temperature, which - independently of air temperature - is known to influence the survival, growth and dry matter partitioning of field plants (Smith, 1989). Leaf abscission in the dry season was noticeably lower in plants that grew under the mulch treatments (data not shown). Previous studies in cacao have shown that conserved soil moisture has a positive influence on leaf area duration (Joly and Hahn, 1989b).

There was a clear benefit to early yield of the coffee husk mulch treatment, which was comparable to trees grown under irrigation and higher than those grown with the plastic mulch (Figure 6). A likely explanation for this is that the coffee husk mulch would have added nutrients to the soil as well as conserving water. Where coffee husks are not available locally, many other potential mulching materials are readily available to the Ghanaian farmer. These include wood shavings, weeding trash, rotten plantain pseudostems, fallen litter such as dry cacao leaves and, where phytosanitary issues will not arise, cocoa bean shells (e.g. Amoah et al., 2005). Further research to determine the suitability of possible mulching materials for use during cacao establishment would be appropriate. Where organic materials are not available locally, use of plastic mulching may provide a more cost-effective alternative since, firstly, they are considerably less bulky to transport and, secondly, they can be re-used in subsequent years.

Currently smallholder cacao farmers use seed-derived planting material in West Africa. The speed at which some farmers might move towards using clonal material in the future is the subject of some debate. The results demonstrated that when grafted material was used high losses were incurred when no mulching treatment and only light shade was present (Figure 4). Furthermore, the fact that there were greater plant losses of some cacao genotypes under the zero mulch treatment suggests that, with respect to survival, some genotypes are better able to survive under conditions of low soil water. Under the zero mulch treatment P 30 [POS] and SCA 6 experienced greater losses compared to that under the mulch treatments than T 79/501 and PA 150 (Figure 4), which appear to be better able to survive under water limited conditions, either through a greater ability to conserve water and/ or to extract water as a result of a more vigorous root system (note that it was not possible to look at the rooting system in the current study). Clonal differences in establishment were observed by Toxopeus (1970b) in Nigeria, although that study used rooted cuttings rather than grafted materials.

The observation that plants subjected to the heavier shade treatments survived better (Figure 4) may be explained in terms of the benefits that shade provides for young cacao (with little selfshading) especially in the dry season. The micro-meteorological data collected here are consistent with the views of Anim-Kwapong (2003) and Acheampong et al. (2013) that shade can ameliorate stressful conditions in the microenvironment through the reduction of daytime water vapour pressure deficit (Table 2). Other cited benefits of shade include protection against high photoinhibition, excessive transpiration and leaf abscission (Joly and Hahn, 1989b). The results presented here demonstrate an additive effect of mulching and shading on photosynthetic assimilation and a consequent impact on survival (Figures 3 and 4). Comparable synergistic effects 
on cacao have been reported to exist between irrigation and fertiliser application (Jadin and Jaquemart, 1978).

Only slight differences were noted in plant growth under the different shade intensities (Figure 5). Therefore, the increased survival of plants under the heavier shade treatments more than compensated for any negative effects of competition from the shade plants. Nevertheless, good shade management is important to maximise growth and productivity. In particular, reduced shade may be important in the rainy seasons, when cloud cover is higher, to promote faster plant growth. Throughout the work no clear differences were observed in the photosynthetic rates of the four genotypes (Figure 3). Most likely the differences in stem growth and yield are a reflection of differences in canopy architecture and/or the proportion of assimilate that is partitioned into stem growth, pod and bean production (Daymond et al. 2002).

To conclude, this experiment has shown that more vigorous clones establish better. It has also shown that application of irrigation or mulching can be used to maintain higher soil water levels during dry periods thus improving early growth and survival of cacao. Furthermore, the experiment has demonstrated that use of appropriate shading can increase early survival rates and that there is a level of additivity between mulching and shading on plant survival and growth. In practice, whilst irrigation (2.7 litres of water applied twice a week to each young cacao tree) was an effective intervention, this may not always be a practical option for many West African smallholder farmers, who may face limited access to water supplies and materials. There is an interest in the establishment of a small number of larger plantations in parts of West Africa, where the use of irrigation may be a viable option. In such circumstances we would recommend its use at the establishment phase when atypical rainfall failure occurs in the traditional rainy seasons and in the dry season. The quantity needed should be adjusted according to prevailing climate conditions and soil types. In the absence of irrigation provision, which is the case on most smallholdings, mulching combined with appropriate shading provides an effective alternative to significantly improve establishment rates.

Acknowledgements. The authors are grateful to Hakeem Rashied and Godwin Addo of the Cocoa Research Institute of Ghana (CRIG) for providing technical support and to the Cocoa Research Association (a UK- based non-profit scientific research organisation that is currently supported by Mars Wrigley Confectionery, Mondelez International and ICE Cocoa Futures Europe) the CFC and the Ghana COCOBOD for part-funding this work. This paper is published with the kind permission of the Executive Director of CRIG.

\section{REFERENCES}

Acheampong, K., Hadley, P. and Daymond, A. J. (2013). Photosynthetic activity and early growth of four cacao genotypes as influenced by different shade regimes under West African dry and wet season conditions. Experimental Agriculture 49(1): 31-42.

Ahenkorah, Y., Akrofi, G. and Adri, A. K. (1974). The end of the first shade and manurial experiment at the Cocoa Research Institute of Ghana. Journal of Horticultural Science 49: 43-49. Amoah, F. M., Opoku-Ameyaw, K., Osei-Bonsu, K. and Oppong, F. K. (2005). The effect of 
mulch on the establishment and early yield on cocoa. In $14^{\text {th }}$ International Cocoa Research Conference, Accra, Ghana, 13-18 October 2003, 1301-1308.

Anim-Kwapong, G. J. (2003). Potential of some neotropical Albizia species as shade trees when replanting cacao in Ghana. Agroforestry Systems 58: 185-193.

Ayanlaja, S. A. (1983). Rehabilitation of cocoa (Theobroma cacao L.) in Nigeria: major problems and possible solutions. I. Causes of difficulty of seedling establishment. Plant and Soil 73: 403409. Balasimha, D., Daniel, E. V. and Bhat, P. G. (1991). Influence of environmental factors on photosynthesis in cacao trees. Agriculture and Forest Meteorology 55: 15-21.

Carr, M. K. V. and Lockwood, G. (2011). The water relations and irrigation requirements of cocoa (Theobroma cacao): a review. Experimental Agriculture 47: 653-676.

Daymond, A. J., Hadley, P., Machado, R. C. R. and Ng, E. (2002). Genetic variation in partitioning to the yield component of cacao (Theobroma cacao L.). Hortscience 37: 799-801.

Daymond, A. J. and Hadley, P. (2004). The effects of temperature and light integral on early vegetative growth and chlorophyll fluorescence of four contrasting genotypes of cacao (Theobroma cacao). Annals of Applied Biology 145: 257-262.

Daymond, A. J., Tricker, P. and Hadley, P. (2011). Genotypic variation in photosynthesis in cacao is correlated with stomatal conductance and leaf nitrogen. Biologia Plantarum 55: 99-104. Frimpong, E. B. and Akuoko, S. (1995). The combined effects of mulching and water absorbed polymers on the establishment of cocoa in drought prone areas. Annual Report, Cocoa Research Institute, Ghana 1993-94: 59-60.

Galyuon, I. K. A., McDavid, C. R., Lopez, F. B. and Spence, J. A. (1996). The effect of irradiance level on cacao (Theobroma cacao L.) : II. Gas exchange and chlorophyll fluorescence. Tropical Agriculture (Trinidad) 73(1): 29-33.

ICCO (2016). August Quarterly Bulletin of Cocoa Statistics.

Jadin, P. and Jacquemart, J. P. (1978). Effet de l'irrigation sure la précocité des jeunes cacaoyères. Café Cacao Thé 22(1): 31-36.

Jagoret, P. and Jadin, P. (1992). Recherche d'un itinéraire technique pour la replantation des cacaoyères au Togo. III. Premier résultats des innovations techniques proposes en milieu paysan pour la replantation des cacaoyères. Café Cacao Thé 36(4): 269-278.

Joly, R. J. and Hahn, D. T. (1989a). Net $\mathrm{CO}_{2}$ assimilation of cacao seedlings during periods of plant water deficit. Photosynthesis Research 21: 151-159.

Joly, R. J. and Hahn, D. T. (1989b). An empirical model for leaf expansion in cacao in relation to plant water deficit. Annals of Botany 64: 1-8.

Liu, C. A., Jin, S. L., Zhou, L. M., Jia, Y., Li, F. M., Xiong, Y. C. and Li, X. G. (2009). Effects of plastic film mulch and tillage on maize productivity and soil parameters. European Journal of Agronomy 31(4): 241-249.

Malhi, Y. and Wright, J. (2004). Spatial patterns and recent trends in the climate of tropical rainforest regions. Philosophical Transactions of the Royal Society B 359: 311-329.

Oliet, J., Plannelles, R. Segura, M. L., Artero, F. and Jacobs, D. F. (2004). Mineral nutrition and growth of containerized Pinus halepensis seedlings under controlled-release fertilizer. Scientia Horticulturae 103: 113-129.

Owusu, K. and Waylen, P. R. (2013). The changing rainy season climatology of mid-Ghana. Theoretical and Applied Climatology 112(3-4): 419-430. 
Raja Harun, R. M. and Hardwick, K. (1988). The effect of different temperatures and water vapour pressure deficits on photosynthesis and transpiration of cacao leaves. In $10^{\text {th }}$ International Cocoa Research Conference, Santo Domingo, Dominican republic, 17-23 May 1987, 211-214.

Smith, B. G. (1989). The effects of soil-water and atmospheric vapour-pressure deficit on stomatal behaviour and photosynthesis in the oil palm. Journal of Experimental Botany 40: 647-651. Smyth, A. J. (1966). The selection of soils for cacao. Soils Bulletin No. 5:52-53. Rome: Food and Agriculture Organization of The United Nations.

Stanturf, J. A., Warren, M. L., Charnley, S., Polasky, S. C., Goodrich, S. L., Armah, F. and Nyako, Y. A. (2011). Ghana Climate Change vulnerability and Adaptation Assessment. U.S. Agency for International Development, Washington, USA.

Toxopeus, H. (1970). Establishment ability of cacao progeny in Nigeria. Euphytica 19: 327-333. Toxopeus, H. (1970b). Seasonal trend of the rooting success of cuttings of cacao clones in Nigeria and the relation with establishment. Euphytica, 19, 426-429.

Wasowicz, T. E. and Havord, G. (1951). Ten years of a mulching experiment on cacao. A Report on Cacao Research 1945-51, 98-103 Trinidad: The Imperial College of Tropical Agriculture Trinidad.

\section{TABLE CAPTIONS}

Table 1. Soil fertility of the experimental site compared with standard soil ratings for cacao (Smyth, 1966).

Table 2. Mean daytime ( $0600 \mathrm{~h}$ to $1800 \mathrm{~h}$ ) relative humidity, air temperature and vapour pressure deficit under different shade regimes and in different seasons. (Each value represents the mean data recorded from three dataloggers across each season).

\section{FIGURE CAPTIONS}

Figure 1. Soil moisture under mulch treatments at different depths during the dry season of 2007/2008. Each bar represents the mean value for two plots per treatment, each measured twice.

Figure 2. Stomatal conductance of four cacao clones (SCA 6: A and B; T 79/501: C and D; P 30 [POS]: $\mathrm{E}$ and F; PA 150: $\mathrm{G}$ and $\mathrm{H}$ ) across the three seasons under different mulch treatments in the first year (A, C, E, and G) and second year after establishment (B, D, F, and H). Each bar represents the mean value for 12 plants.

Figure 3. Net photosynthesis of four cacao clones (SCA 6: A and B; T 79/501: C and D; P 30 [POS]: $\mathrm{E}$ and F; PA 150: $\mathrm{G}$ and $\mathrm{H}$ ) across different seasons and under different mulch treatments in the first year (A, C, E, and G) and second year after establishment (B, D, F, and H). Each bar represents the mean value for 12 plants. 
Figure 4. Field survival of four cacao clones (SCA 6: A and B; T 79/501: C and D; P 30 [POS]: E and F; PA 150: G and H) under different mulch and shade treatments after one (A, C, E, and G) and two $(\mathrm{B}, \mathrm{D}, \mathrm{F}$, and $\mathrm{H})$ years after planting. Each bar represents $\%$ plants surviving out of 48 $(=100 \%)$.

Figure 5. Stem volume of four cacao clones (SCA 6: A and B; T 79/501: C and D; P 30 [POS]: E and F; PA 150: $\mathrm{G}$ and $\mathrm{H}$ ) under different mulch and shade treatments after one (A, C, E, and $\mathrm{G})$ and two $(\mathrm{B}, \mathrm{D}, \mathrm{F}$, and $\mathrm{H})$ years after planting. Each bar represents the mean value for 24 plants.

Figure 6. Dry cocoa bean yield of clonal cacao genotypes SCA 6 (A), T 79/501 (B), P 30 [POS] (C), and PA 150 (D) under different shade and mulching treatments. 
Shade and soil water promote cacao establishment

Table 1 Soil fertility of experimental site compared with standard soil ratings for cacao (Smyth, 1966)

\begin{tabular}{|l|l|l|l|l|l|l|l|}
\hline $\begin{array}{l}\text { Soil fertility } \\
\text { parameters }\end{array}$ & Soil Depth & $\mathrm{pH}$ & $\% \mathrm{~N}$ & $\%$ O. M & $\begin{array}{l}\text { Avail. P } \\
\left(\mu \mathrm{g} \mathrm{g}^{-1}\right)\end{array}$ & $\% \mathrm{C}$ & $\mathrm{C} / \mathrm{N}$ \\
\hline $\begin{array}{l}\text { Experimental } \\
\text { site }\end{array}$ & $0-15 \mathrm{~cm}$ & 5.7 & 0.11 & 1.53 & 7.5 & 0.88 & 8.07 \\
\hline $\begin{array}{l}\text { Experimental } \\
\text { site }\end{array}$ & $15-30 \mathrm{~cm}$ & 5.3 & 0.07 & 0.81 & 4.7 & 0.47 & 7.01 \\
\hline $\begin{array}{l}\text { Medium } \\
\text { rating } \\
\text { (Standard) }\end{array}$ & - & $5.1-5.5$ & $0.2-0.5$ & $2.0-4.2$ & $6.5-13$ & $1.16-2.44$ & $13-20$ \\
\hline $\begin{array}{l}\text { Low rating } \\
\text { (Standard) }\end{array}$ & - & - & $0.1-0.2$ & $1.0-2.0$ & $3.0-6.5$ & $0.58-1.16$ & $>20$ \\
\hline
\end{tabular}

Table 2. Mean daytime ( 6 am to $6 \mathrm{pm}$ ) relative humidity, air temperature and vapour pressure deficit under different shade regimes and in different seasons. (Each value represents the mean data recorded from three dataloggers across each season).

\begin{tabular}{|c|c|c|c|c|c|c|c|c|c|}
\hline \multirow{2}{*}{$\begin{array}{l}\text { Seasons } \\
\text { Shade } \\
\text { Type }\end{array}$} & \multicolumn{3}{|c|}{$\begin{array}{l}\text { Minor rainy season } \\
\text { (mid-July to October } \\
\text { 2007) }\end{array}$} & \multicolumn{3}{|c|}{$\begin{array}{l}\text { Dry season (November } \\
2007 \text { to February 2008) }\end{array}$} & \multicolumn{3}{|c|}{$\begin{array}{l}\text { Major rainy season } \\
\text { (March to mid-July } \\
\text { 2008) }\end{array}$} \\
\hline & $\begin{array}{l}\text { R.H. } \\
(\%)\end{array}$ & $\mathrm{T}^{\circ} \mathrm{C}$ & $\begin{array}{l}\text { VPD } \\
\mathrm{kPa}\end{array}$ & $\begin{array}{l}\text { R.H. } \\
(\%)\end{array}$ & $\mathrm{T}^{\circ} \mathrm{C}$ & $\begin{array}{l}\text { VPD } \\
\mathrm{kPa}\end{array}$ & $\begin{array}{l}\text { R.H. } \\
(\%)\end{array}$ & $\mathrm{T}^{\circ} \mathrm{C}$ & $\begin{array}{l}\text { VPD } \\
\mathrm{kPa}\end{array}$ \\
\hline Light & 82.50 & 25.2 & 0.56 & 55.25 & 34.2 & 2.41 & 66.50 & 31.4 & 1.54 \\
\hline Medium & 83.50 & 24.9 & 0.52 & 56.25 & 33.8 & 2.30 & 75.25 & 30.5 & 1.08 \\
\hline Heavy & 85.00 & 23.9 & 0.45 & 58.00 & 32.6 & 2.07 & 81.25 & 30.8 & 0.83 \\
\hline
\end{tabular}




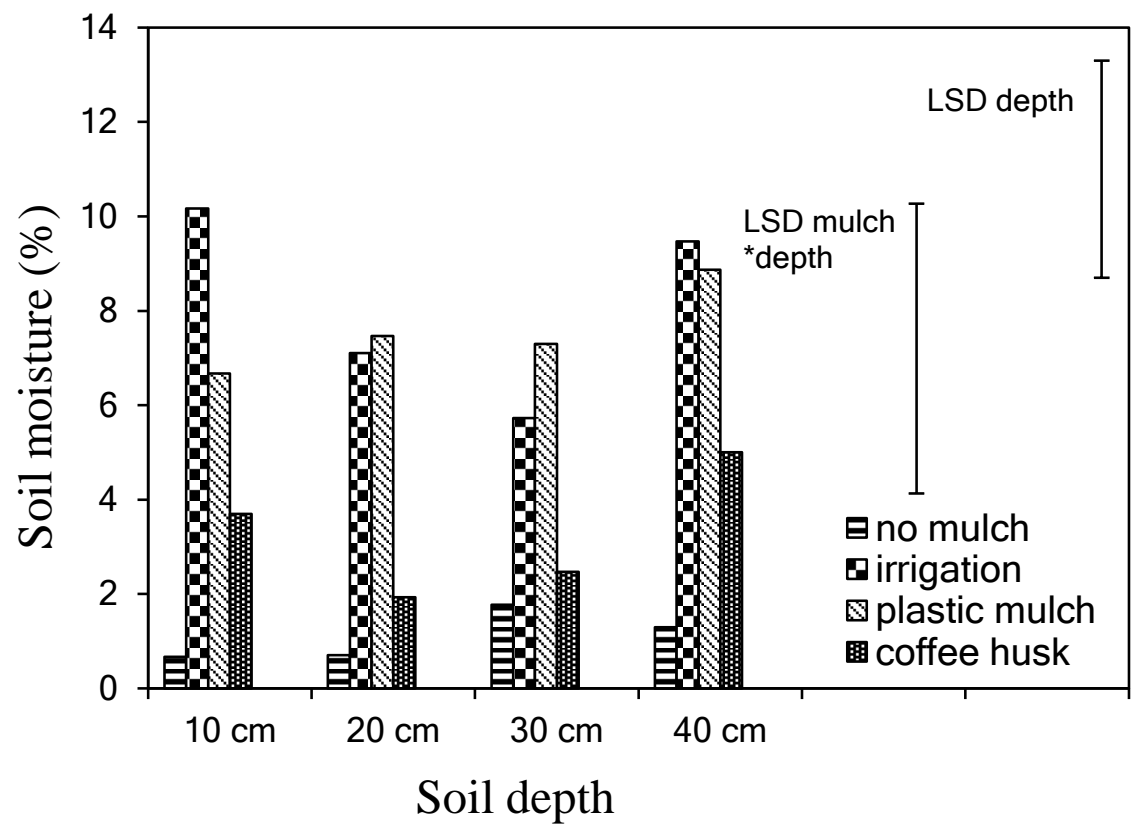

FIGURE 1 

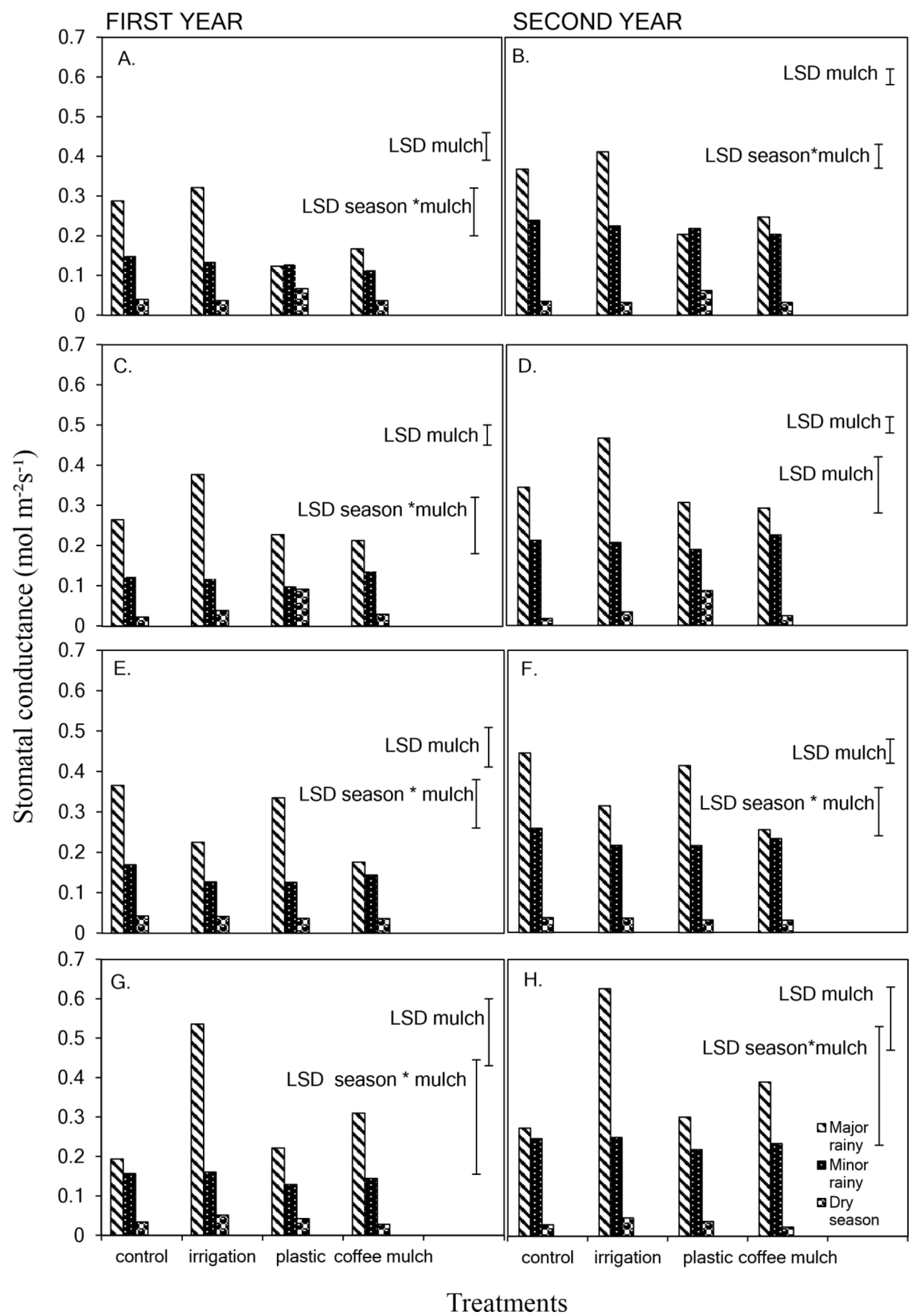

FIGURE 2 

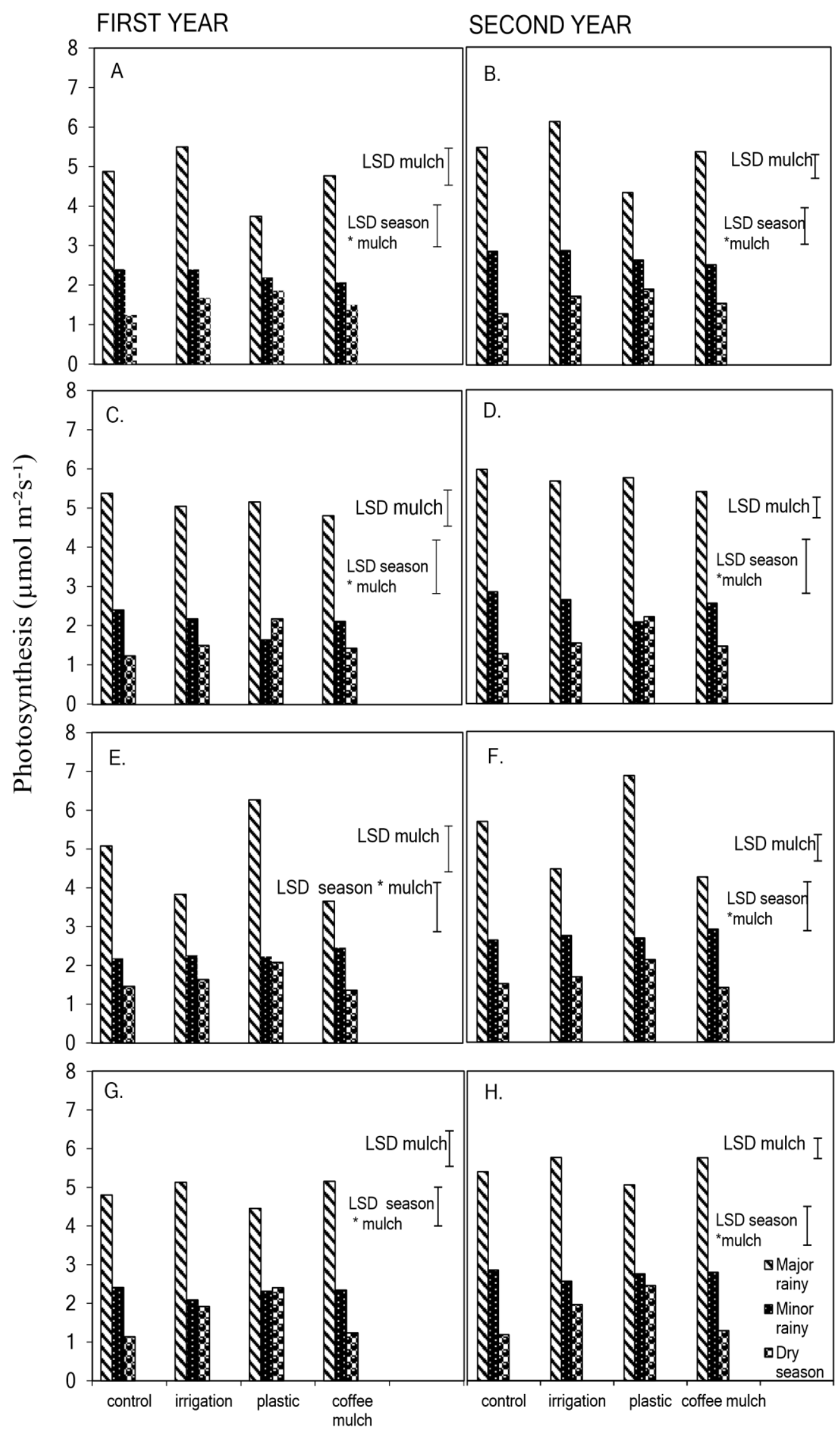

FIGURE 3

Treatments 

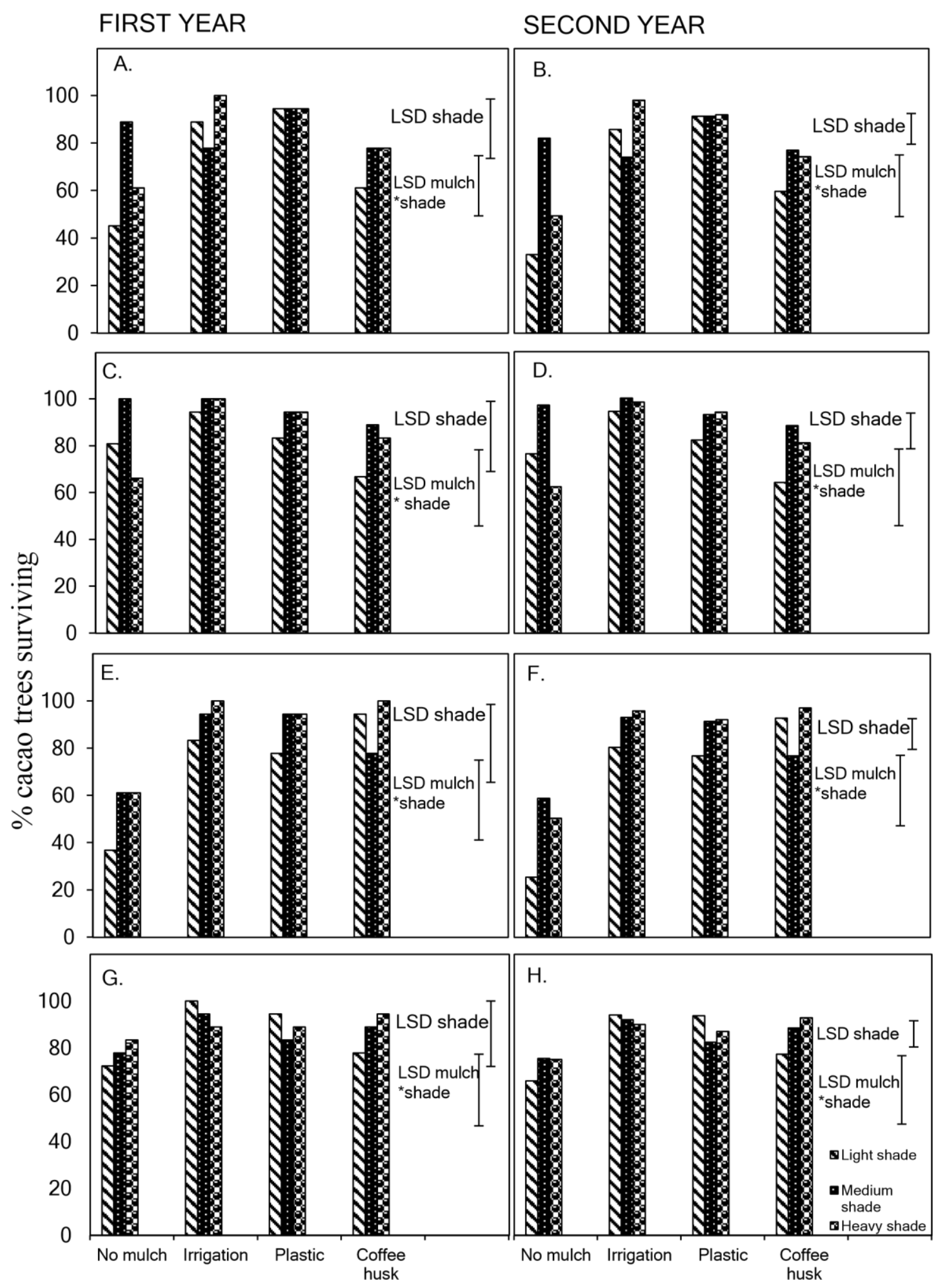

Treatments

FIGURE 4 


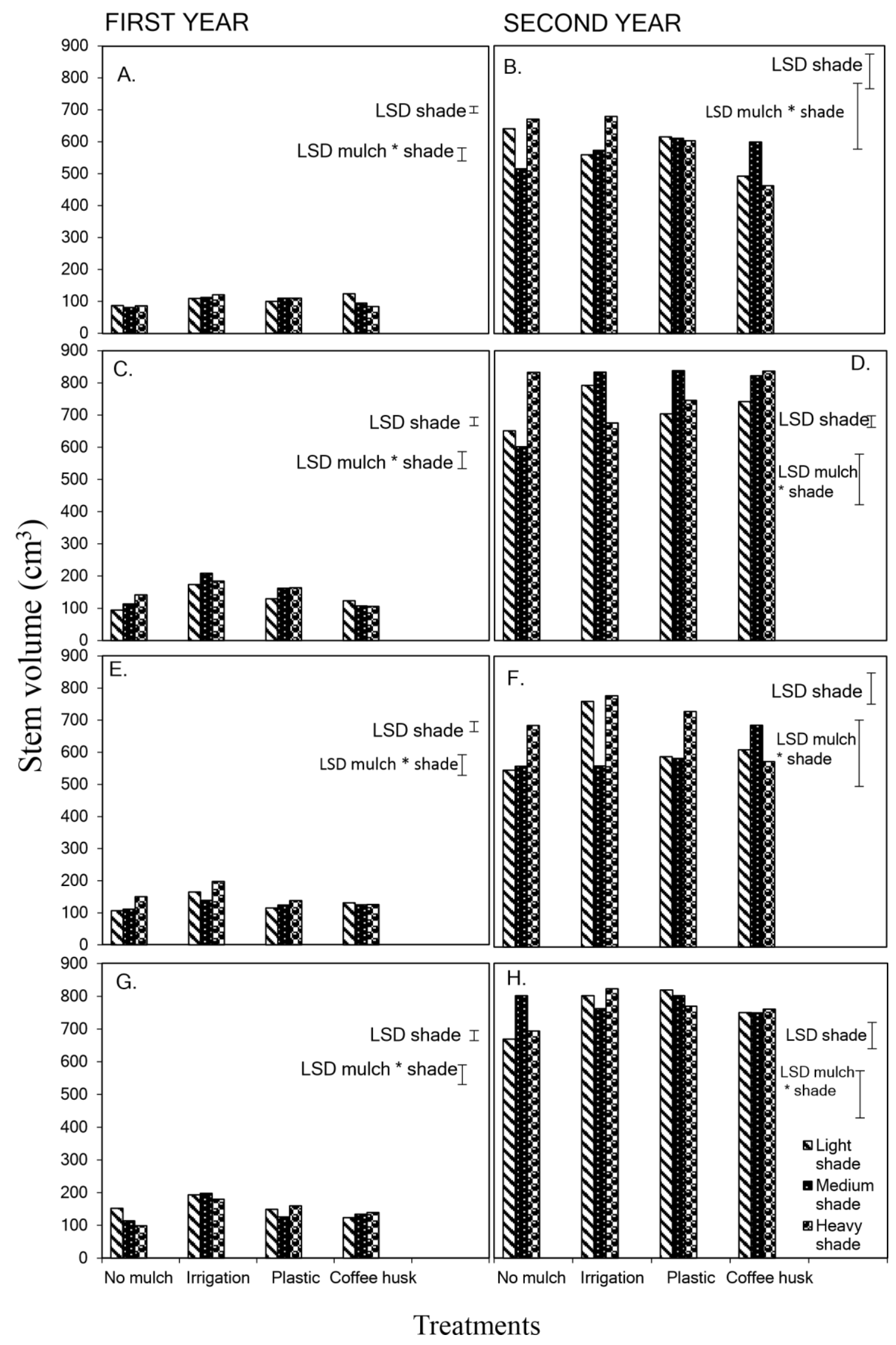

FIGURE 5 


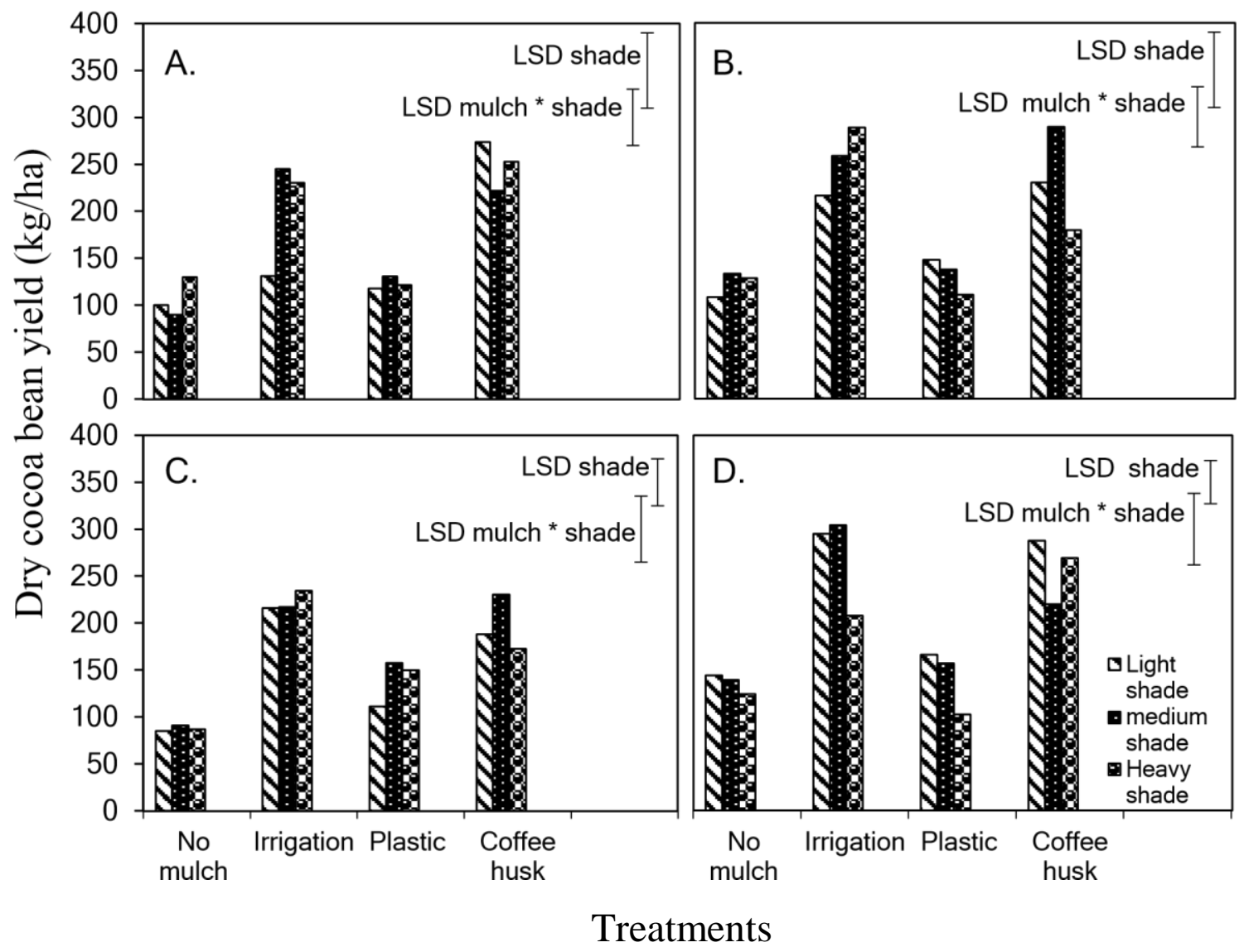

FIGURE 6 
Figure 